\title{
Study on Fault Tolerant Switched Reluctance Machines
}

\author{
Mircea Ruba, Loránd Szabó, Larisa Strete, Ioan-Adrian Viorel \\ Technical University of Cluj, Romania \\ 15, Daicoviciu str., 400020 Cluj, Romania \\ Tel: (+40)-264-401827, fax: (+40)-264-593117 \\ e-mail: Mircea.Ruba@mae.utcluj.ro
}

\begin{abstract}
The paper's goal is to compare a usual switched reluctance machine and a fault tolerant variant of it. By coupled Flux 2D and Simulink transient simulations the behaviour of the fault tolerant drive system under different winding fault conditions were studied. It was proved that using the proposed machine structure and converter topology same torque capability of the machine in faulty states as in healthy conditions can be assured. A short discussion on fault-tolerant converters is included in the paper, too.
\end{abstract}

\section{INTRODUCTION}

The concept of fault tolerance emerged in the field of information technology because of the demand of safety and reliability of a system. Later on more and more fields of engineering took over the concept, and the connection between fault tolerant equipments formed fault tolerant systems [1].

The meaning of system is the interconnection of components all reaching for the same goal, to serve an output for a given application. As errors are part of life, the possibility of their appearance in a system must be taken into account.

Nevertheless fault tolerant systems are not so easy to achieve. A fault tolerant system must detect faults in its components and also must have the ability either to correct it (for example by switching to a backup unit when the main one fails) or to circumvent it (for example by reconfiguring the system) [2].

Nowadays the tendency in electrical engineering is to develop applications as safe as possible. The concept of fault tolerant device became a purpose for a lot of researchers. With the help of electrical power devices that evolved in the last years a combination between electric drives and machines pushed the limits of fault tolerance [3]. Any attempt of study in this area that exposes new results can become of important interest for all researchers working in the field of fault tolerance.

In the electrical machine designs, fault tolerant variants required not only for structure modifications, but also for special winding connections and intelligent electronic devices. To compensate the higher costs demanded by a more complex power converters the use of a relatively simple machine is imposed.

To reach this goal, the switched reluctance motor (SRM) is considered as an optimum solution for the problem. Unfortunately by increasing the machine's fault tolerance its losses could be greater and its efficiency less than for its customary counterpart.

Thanks to the improvements in the field of power electronics and also to digital signal processing nowadays intelligent solutions can be provided in designing a fault tolerant electrical drive system. The separate phase feeding and control of the machines allow an easier approach of the fault tolerant tasks, offering better results [4]

The electrical machines in study were compared by means of simulation. The models were built up using specific software packages. One, Flux 2D, was used for modelling the machine using finite element method (FEM). The second, the MATLAB-Simulink environment was applied for modelling the inverter's control system and to generate the faults for the studied cases. These two programs were coupled and worked together using the Flux-to-Simulink Technology. This way it was possible to study in details all the typical faulty states of the motor.

\section{THE PURPOSED SRM STRUCTURE}

Achieving a fault tolerant variant of a usual electrical machine requires modified topologies. In order to develop an efficient fault tolerant electrical machine is important to take into account also its losses.

The main idea was to shorten the flux paths in the new motor structure, hence the shorter flux paths means lower iron losses.

As a starting point in the study, a 12/8 SRM structure was considered, as that shown in Fig. 1.

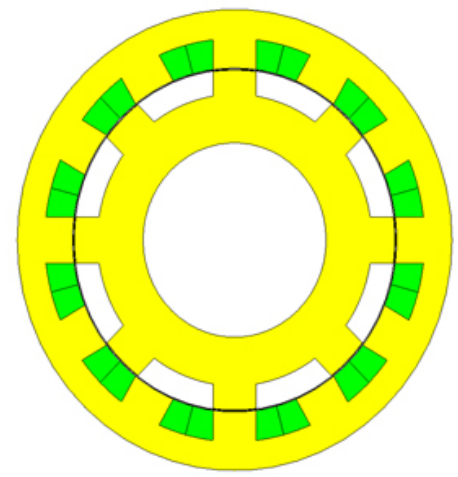

Fig. 1. The initial SRM structure

The machine has 12 concentrated coils wound around each stator pole. Two coils from opposite poles are adequately 
connected together to form a phase. Hence there are 6 phases. This structure was selected because it can be transformed relatively easily in a fault tolerant variant. The proposed modifications are implying both the rotor structure [5] and the connection of the windings.

The modified SRM has 14 rotor poles, as shown in Fig. 2.

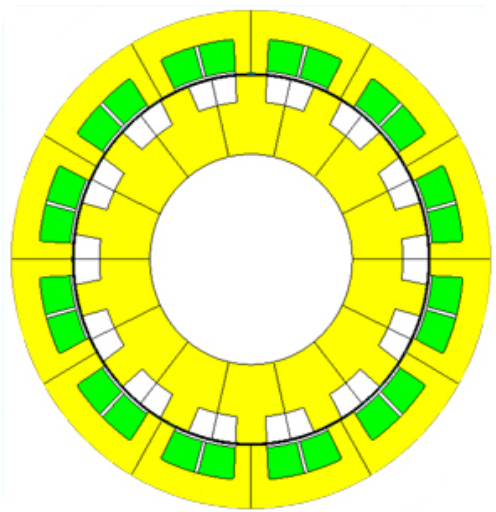

Fig. 2. The fault-tolerant SRM structure

Changing the way of flux path crossing the air-gap and closing in adjacent stator poles (see Fig. 3) was the first idea for achieving an efficient fault tolerant SRM.

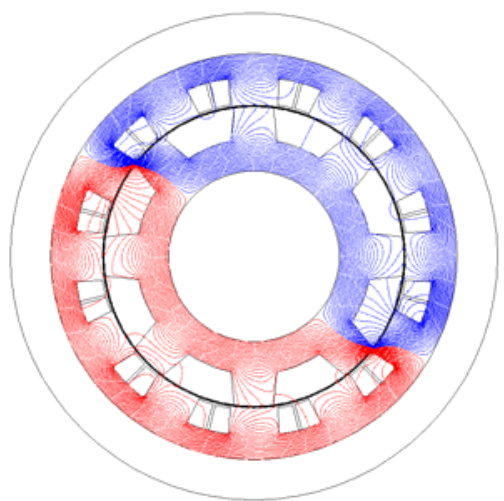

a) The initial SRM

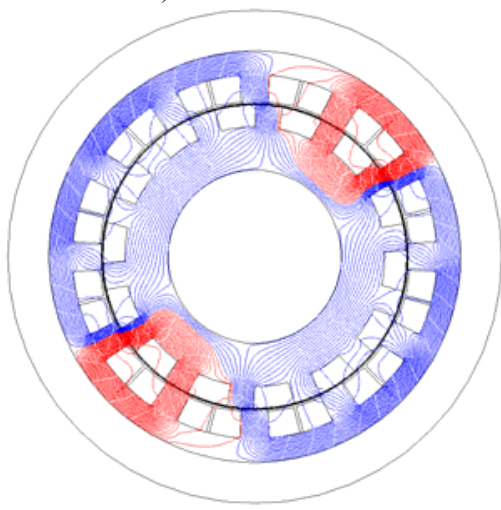

b) The fault-tolerant SRM

Fig. 3. The flux lines in the SRM machines

In such a rotor design at each moment two pairs of adjacent stator poles are used for the torque development. So at each time two adjacent phases are fed, which means hence in total 4 coils. This connection helps the motor to overrun the poles with faulty phases and to minimize the torque ripple.
The winding scheme is a six phase duplex type, in other words each phase is doubled. This consists in phases placed at an angle of 180 mechanical degrees, in order to create the correct force distribution in the machine. In case of a fault on one channel the second one still will contribute to the torque generation and by its independence, in means of feeding and control on each channel, the fault tolerance is achieved.

Both machines in study have the same stator, but they have different rotors and different phase/channel connections. Multiplication of rotor poles will increase the level of fault tolerance in means of torque development and safe operation.

To emphasize the difference between the two sample motors in study their geometrical dimensions are given in the Table I.

TABLE I

The GeOMETRICAL Dimensions For the Two MACHINES

\begin{tabular}{|c|c|c|}
\hline & $\begin{array}{c}\text { Usual topology } \\
\mathbf{1 2 / 8}\end{array}$ & $\begin{array}{c}\text { Proposed topology } \\
\mathbf{1 2 / 1 4}\end{array}$ \\
\hline Stator outer diameter[mm] & 190 & 190 \\
\hline Stator inner diameter[mm] & 141 & 141 \\
\hline Stator pole depth [mm] & 12 & 12 \\
\hline Rotor outer diameter[mm] & 140 & 140 \\
\hline Rotor inner diameter[mm] & 120 & 120 \\
\hline Active stack length[mm] & 315 & 1000 \\
\hline Air-gap[mm] & 0.8 & 0.8 \\
\hline
\end{tabular}

\section{The POWER CONVERTER TOPOLOGY In STUdy}

The control system has to have the intelligence to detect the fault, to isolate it, mask it and remedy it, all in a manner as its behaviour to be influence as less as possible [6], [7]. In the fault tolerant concept, this is the main imposed task for a drive. For this, the complete separation between phases became an obligatory requirement [8].

The proposed converter has a separate H-bridge connection for every coil in order to be able to control each one independently, as requested by the fault tolerant design (see Fig. 4).

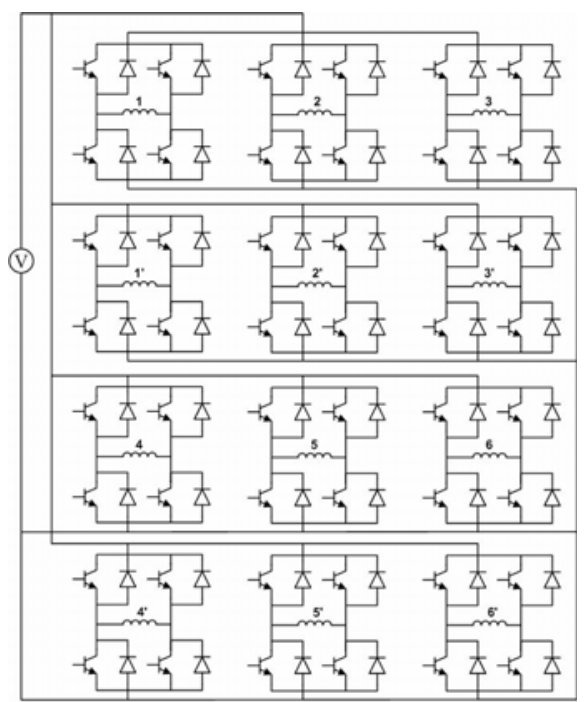

Fig. 4. The complex power converter 
The parallel connection to the bars is a second achievement that sets the fault tolerance to a higher level.

The simulation of the power converter is performed by using an electrical circuit build up in Electriflux, Flux 2D's circuit editor, and attached to the FEM model of the machine.

The electrical circuit attached to one phase is given in Fig. 5. As it can be seen each channel of one phase is modelled using two electrical coils, corresponding to the "come and go" sides of the winding.

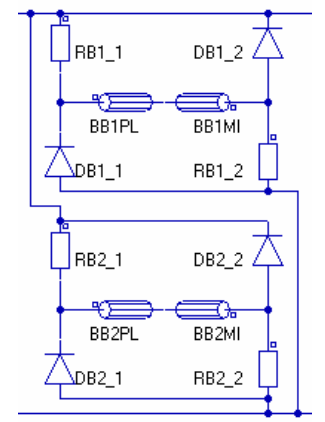

Fig. 5. The electrical circuit of one phase

The reverse current management is handled by the diodes. In the electric circuit model the power switches were replaced by resistors. Practically these resistors will model the switches, by changing their resistance from a high value, as for the OFF state of the switch, to a low one, corresponding to the ON state of the transistor. These changes are obtained using the coupling of Flux 2D with MATLAB-Simulink. In fig. 6 the Simulink model of the entire SRM based fault tolerant drive system is given.

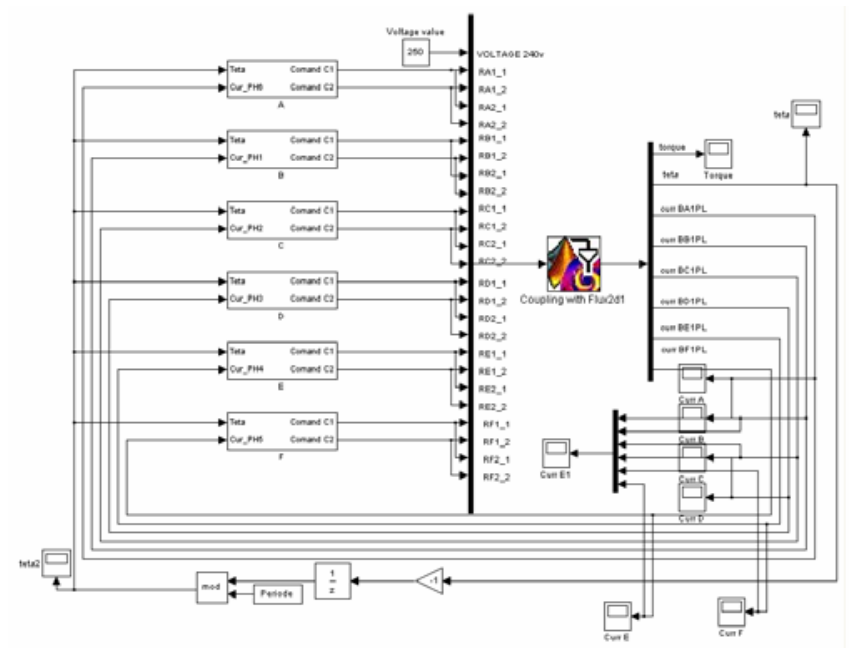

Fig. 6. The Simulink application for the command stage

As it can be seen there are 6 blocks generating the phase currents upon the PWM technique.

When each step is computed, the results are sent to the Flux 2D model, and a response (concerning the position, torque and phase currents) is obtained after the field computations, and is sent back to the Simulink model. The next step is computed based on these feedback values, so the system operates in closed reaction loop. The firing angles are defined versus the rotor position, and the values are set from an outside m-type file, together with the maximum current value and the changing switch resistance values.

As it was mentioned previously for the proposed new 12/14 topology the winding is a 6-phase one, and for each phase there are two coupled channels. To be able to compare the two machines the $12 / 8$ poles SRM variant was designed with a 3-phase winding, each phase having 2 connected channels. Hence for each phase, four stator poles correspond.

In order to perform the coupled simulations some parameter adjustments are required. Two programs are coupled together, both needing high computer resources. Therefore a compromise had to be taken when lowering the mesh density in order to obtain affordable computation time but, in meantime, not to decrease the precision of the results.

The PWM technique is used only on one switch of one phase, the second one is held open for the whole conducting period, hence practically the first modulates the current. The $\mathrm{ON} / \mathrm{OFF}$ signals are sent to the two switches $(\mathrm{C} 1$ and $\mathrm{C} 2$ in fig. 7.): the resistance value of $100 \mathrm{k} \Omega$ (OFF state) or $0.004 \Omega$ (ON state). The faults will be simulated by imposing OFF state for both switches of one phase. The precision of the PWM is set by the hysteresis band around the imposed current.

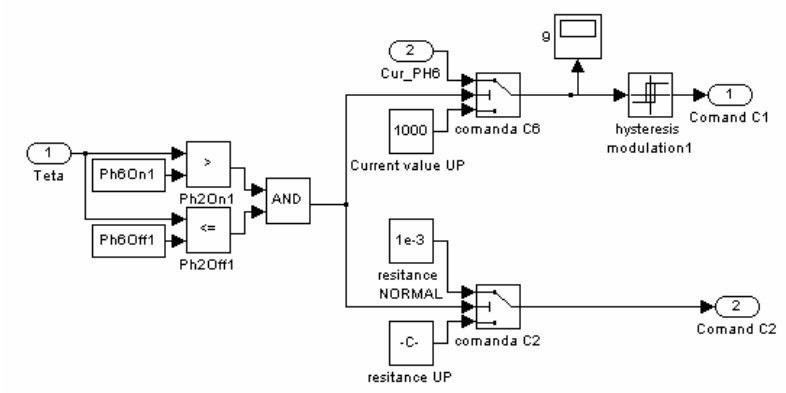

Fig. 7. Detail on one phase's command block

The electrical circuits and the Simulink schemes are given only for the 12/14 topology. For the classical 12/8 one these are closely alike.

For the present study, the velocity was imposed for both machines the same, $600 \mathrm{r} / \mathrm{min}$. The considered regime is a stable one, so no transient start-up was imposed. The interest is concentrated on the machine's behaviour in passing from normal operation to a faulted regime

\section{RESUlts OF SimUlations}

Different cases were studied in order to compare the two machine's geometries and to check their fault tolerance capability:

i.) normal operating mode (reference case),

ii.) open circuit of one channel,

iii.) open circuit of one phase,

iv.) open circuit of two channels from different phases,

v.) open circuit of one phase and one channel from a different phase (worst case in study). 
Different computation times were set for the two machines, in a way to be able to observe the effects of the faults. The 6-phase (12/14) machine was simulated $0.008 \mathrm{~s}$ and the other one $0.024 \mathrm{~s}$.
In Fig. 8 the current and torque waveforms versus time for the healthy and for all the four faulty cases for both SRM structures are presented.
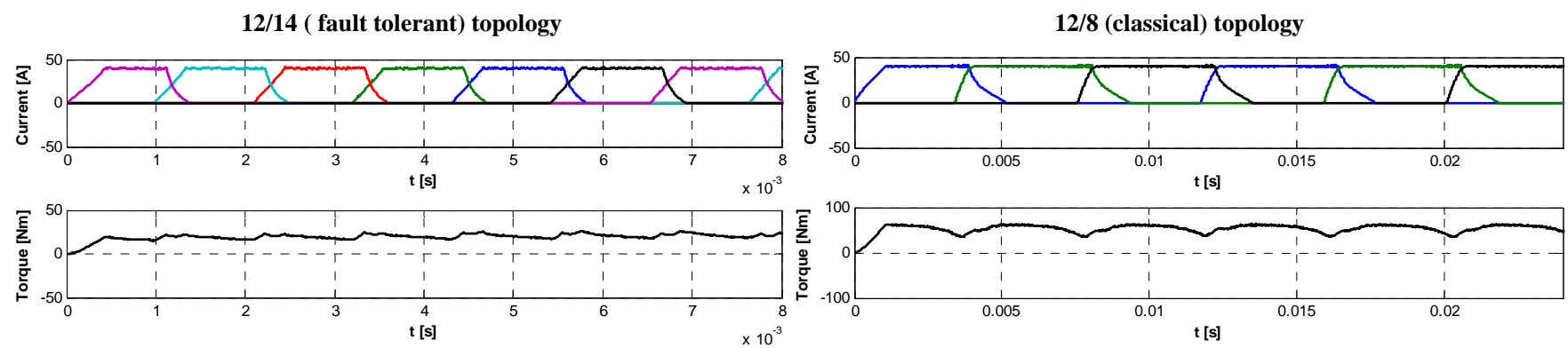

a) normal study case
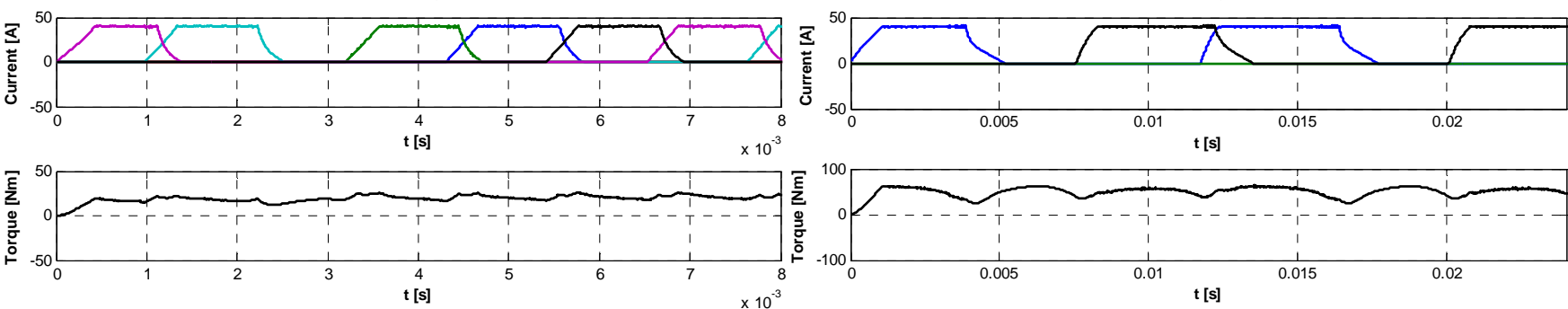

b) one channel open circuit
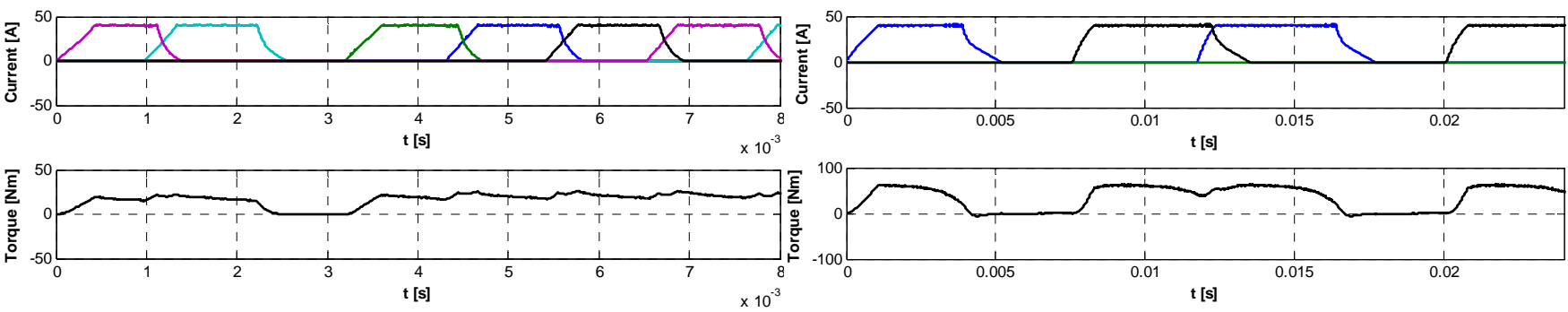

c) one phase open circuit

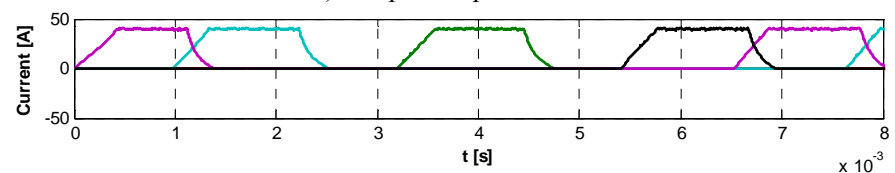

h) one phase open circuit

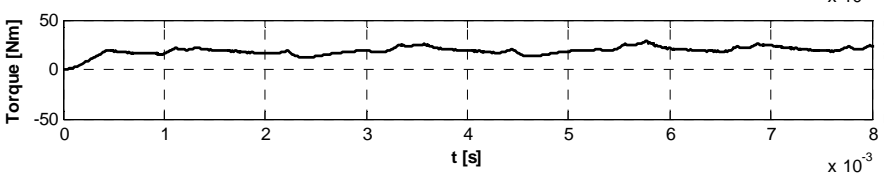

d) two channel open circuit

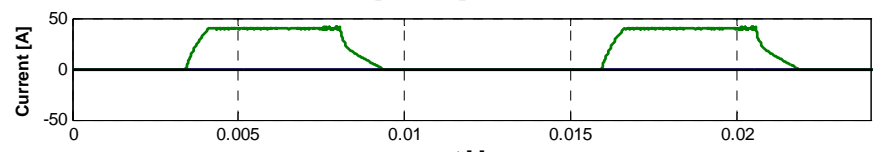

$\mathrm{t}[\mathrm{s}]$

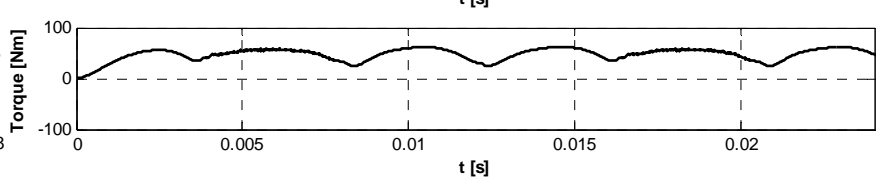

i) two channel open circuit
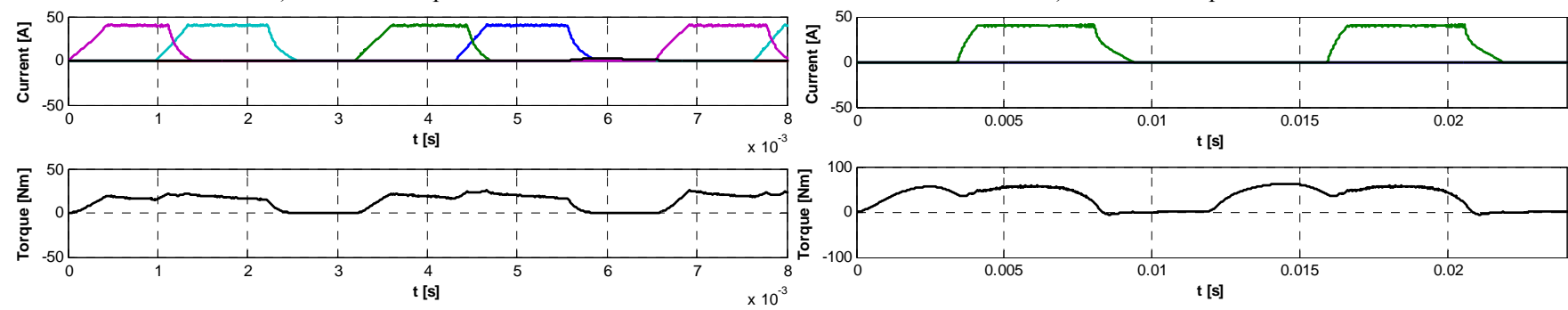

e) one phase and one channel open circuit

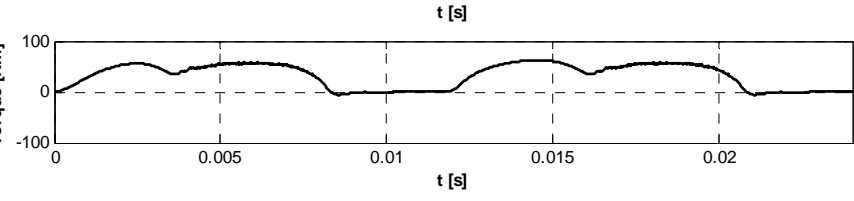

j) one phase and one channel open circuit

Fig. 8. Current and torque plots of the two machines in study under different faulty conditions 
As it can be seen in Fig. 8 there is a short transient period till the current reaches its maximum value. The mean torque developed in normal operating mode is the reference value in this study.

As mentioned above several faulty cases were simulated in order to study the faulty machine's dynamic behaviour.

For both machine structures, the imposed faults were the same. Also the feeding voltage, the current value and the electric parameters of the windings were set identical, therefore a correct comparison of the two machines can be performed.

In Table II the main parameters are given for both SRM structures.

TABLE II

THE EleCtRICAL PARAMETERS OF THE TWO MACHINES

TAKEN INTO STUDY

\begin{tabular}{|c|c|}
\hline Voltage & $250 \mathrm{~V}$ \\
\hline $\begin{array}{c}\text { Reference phase } \\
\text { current }\end{array}$ & $40 \mathrm{~A}$ \\
\hline Input phase power & $10 \mathrm{~kW}$ \\
\hline Phase resistance & $1.2 \Omega$ \\
\hline $\begin{array}{c}\text { No. of turns per } \\
\text { phase }\end{array}$ & 100 \\
\hline
\end{tabular}

In the plots in Fig. 8 the effects of faults can be observed as missing currents and decreasing torques, corresponding to the faulty windings.

Cases a) and f) are for the normal operating modes. The obtained values are considered as reference for the other ones. As it was expected the machine variant with higher number of phases and stator poles have lower torque ripples. In the figures the amplitude of the ripples can be clearly observed.

One channel open circuits are cases b) and g). Due to the missing channel currents the torque is lower and its ripple is higher.

When an entire phase is faulty (Fig. $8 \mathrm{c}$ and $8 \mathrm{~h}$ ) the torque is falling to zero, because inertia and the resistive torque are nil, since no-load condition was studied.

In the case of the 12/14 topology (having a 6 phase winding), the fault on a single phase influences less the torque development capacity then for the $12 / 8$ structure with a three-phase winding.

In the situation of the faults on two different channels from two different phases (Fig. 8d and 8i) the torque ripple is greater at both machines, but the ripple of the 12/8 topology is more high than in the case of the 12/14 one.

The worst case in study is the fault of an entire phase, and a second fault on one channel from different phase. The torque of both machines taken into study reaches zero, therefore the ripples are the highest in this case.

The results concerning the torque development capability of the two machines are in Table III.
TABLE III

THE MEAN TORQUES OF THE TWO MACHINES FOR ALL THE CASES TAKEN IN STUDY

\begin{tabular}{|c|c|c|}
\hline & Studied cases & $\begin{array}{c}\text { Mean torques }[\mathrm{Nm}] \text { and } \\
\text { percentage of the rated } \\
\text { torque }\end{array}$ \\
\hline \multirow{5}{*}{ 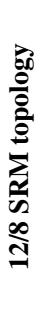 } & Healthy case & $52.21(100 \%)$ \\
\hline & Faulty case 1 & $49.10(94.04 \%)$ \\
\hline & Faulty case 2 & $35.27(67.55 \%)$ \\
\hline & Faulty case 3 & $46.31(88.69 \%)$ \\
\hline & Faulty case 4 & $33.36(63.89 \%)$ \\
\hline \multirow{5}{*}{ 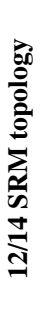 } & Healthy case & $19.93(100 \%)$ \\
\hline & Faulty case 1 & $19.59(98.29 \%)$ \\
\hline & Faulty case 2 & $16.16(81.03 \%)$ \\
\hline & Faulty case 3 & $19.28(96.71 \%)$ \\
\hline & Faulty case 4 & $13.79(69.19 \%)$ \\
\hline
\end{tabular}

The torque ripples are different from a case to another and depend on the fault's gravity.

As seen in the Table III the fault tolerant 12/14 SRM topology is able to develop torque (around $70 \%$ of the rated torque) and continue its movement even at the hardest fault in study, when one phase and one channel from a different phase is damaged.

Obviously the torque ripples are the greatest in this case where the currents are nil. Of course heating and force distribution issues limit the operation in this case of fault. For the 12/8 structure for the same fault the torque ripples are substantially greater during the entire simulation time, due to the low number of phases remained healthy.

Comparing the results from Table III it can be observed that the proposed machine with 12/14 topology has higher torque capability at all the faults in study.

In the case of the first fault in study, nearly full torque is developed (more then $98 \%$ of the rated value), versus the lower torque from the 12/8 (about 94\%).

A main disadvantage of the 12/14 fault tolerant switched reluctance machine is its power converter. This to be also fault tolerant has to be complex, and able to detect and isolate the defects. The inverter (shown in Fig. 4) has 48 power switches and 48 reverse current diodes. Separation of command for each phase or channel will increase the costs.

Upon the demands of specific applications, the electrical drive system (both the power converter and the machine) can be optimised and a compromise between fault tolerance level and manufacturing costs can be made. 
A solution to improve the torque development of a machine in case of faulted windings is to isolate of the defect, and to increase the current in the remaining healthy phases. By this the torque's average value can be held at the same value as in normal operation mode, but the ripples will be greater. This solution can be used only if the windings and the cooling system of the machine were designed to support the greater currents.

Higher currents mean higher temperature and higher losses. Uncontrolled temperature rise can damage the healthy phases, on one side, and on the other, operation at higher currents demand higher power converters.

In our study the current was set identical for both machines, and no current increase in case of faults was considered. The reason was to better compare the two SRM variants as their fault tolerance is concerned.

A lower fault tolerance level can be achieved also with the $12 / 8$ structure by specific winding connections. Each phase is compound of two channels with separate command and feeding. Usually in the case of classic structures a four poled phase, is connected to the same bar and one command sets the firing moment for the entire phase.

\section{CONCLUSIONS}

The comparison of the two SRMs by means of simulations seemed to be the best solution for studying the fault tolerant system. The increasing the rotor pole number is accepted for achieving the fault tolerant system.

To obtain a high level of fault tolerance a complex control system is required and high number machine's pole. The study demonstrated that increasing the number of rotor poles, separating the phases/channels, setting new connections between the existing windings, and using a complex control system will provide the best solution for the fault tolerant SRM based electrical drive system.

In the paper for the $12 / 14$ topology the most complex possibility of separation was presented. In accordance with the application, the level of complexity and of course the tolerance level can be decreased.

The increased number of rotor poles and the complex electronic system that drives and controls the machine means of course higher costs. These costs depend on the level of tolerance implemented in the system.

The coupled simulation program connecting two software environment (FLUX 2D and SIMULINK) was useful in studying the effects of different winding faults on the torque developing capacity of the SRM. The computing power of FLUX 2D thus joined the facilities of Simulink in simply describing the different working regimes of the machines and drives taken into study.

The main problems were regarding the computation times. In order to obtain precise results and reasonable computation time the quality of the FEM model's mesh had to be lowered.

The coupled simulation programs allow a high-quality simulation of closed-loop real time systems.

Future ideas are regarding changes of the machine geometry, and new placing for the windings. A fault tolerant SRM is intended to be built up, using techniques applied in other categories of electrical machines. The resulted structure will be a combination of two already existing machines.

\section{REFERENCES}

[1] Blanke, M., "Diagnosis and Fault-Tolerant Control," Springer Verlag, 2006.

[2] Husain, I., Radun, A., Nairus, J., "Fault Analysis and Excitation Requirements for Switched Reluctance Generators", IEEE Transactions on Energy Conversion, vol. 17, no. 1 (March 2002), pp. 67-72.

[3] Ertugrul, N., "LabVIEW for Electric Circuits, Machines, Drives, and Laboratories," Prentice Hall PTR, 2002.

[4] Heimerdinger, W., Weinstock, C., "A Conceptual Framework for System Fault Tolerance," Technical Report CMU/SEI-92-TR-033, Carnegie Mellon University, Software Engineering Institute, Pittsburgh (USA), 1992.

[5] Ruba, M., Anders, M., "Fault Tolerant Switched Reluctance Machine Study," Proceedings of the International Conference on Power Electronics, Intelligent Motion and Power Quality (PCIM '2008), Nürnberg (Germany), 2008

[6] Mir, S., Islam, M.S., Sebastian, T., Husain, I., "Fault-tolerant switched reluctance motor drive using adaptive fuzzy logic controller," Proceedings. of the IEEE International Electric Machines and Drives Conference (IEMD '03), Madison (WI, USA); vol. 2, pp. 835-841.

[7] Park, B.-G., Kim, T.-S., Ryu, J.-S., Hyun, D.-S., "Fault Tolerant Strategies for BLDC Motor Drives under Switch Faults," Record of the 2006 IEEE Industry Applications Conference, Tampa (FL, USA), vol. 4, pp. 1637-1641.

[8] Kasson, M., Eaves, S., "Fault tolerant motor drive arrangement with independent phase connections and monitor system," Patent no. WO01/91265, 29 November 2001. 